Original Article

\title{
Cryptosporidium spp. OOCYSTS AND Giardia spp. CYSTS IN COATIS (Nasua nasua L. 1766) FROM PARÁ, BRAZIL
}

\author{
Darlene Kássia Saraiva Queiroz Pantoja ${ }^{1}$, Washington Luiz Assunção Pereira ${ }^{1}$, Marcella Katheryne Marques \\ Bernal $^{1}$, Heyde Araújo Tavares ${ }^{2}$, Alana Luanni Messias da Silva ${ }^{2}$, Mônica Cristina de Moraes Silva ${ }^{2}$ \\ ${ }^{1}$ Universidade Federal Rural da Amazônia - UFRA - Belém - Pará. \\ ${ }^{2}$ Instituto Evandro Chagas - IEC - Ananindeua - Pará.
}

\section{A R T I C L E I N F O}

\section{Article history}

Received 29 May 2017

Received in revised form 25 July 2017

Accepted 31 July 2017

\section{Keywords: \\ Enteroprotozoa \\ Procyonids}

Zoonotic potential

\begin{abstract}
A B S T R A C T
Zoonotic enteroparasitosis represent an important public health problem, and species of protozoa such as Cryptosporidium spp. and Giardia spp. can reach high frequencies in regions where basic sanitation conditions are poor, which promotes outbreaks of diarrhea in humans and domestic and wild animals. Wild mammals such as the South American coati (Nasua nasua) feed on insects present in the soil, fruits, and small vertebrates, and are susceptible to contamination by enteroparasites present in the environmental niche. The aim of the present study was to investigate the occurrence of Cryptosporidium spp. and Giardia spp. in N. nasua from a region in the Brazilian Amazon. Fecal samples of 27 coatis two from free-living and 25 from captivity were collected in three different municipalities in the state of Pará, Brazil. The search for Giardia spp. and Cryptosporidium spp. in the collected samples were performed using the direct and Kinyoun methods, respectively, and a commercial immunological test (RIDA®QUICK Cryptosporidium/Giardia Combi. ®R-Biopharm) was used to detect antigens from both parasites. Cryptosporidium spp. oocysts were found in $11.1 \%$ $(3 / 27)$ of the samples; one from a free-living animal and two from captive animals. Giardia spp. cysts were found in $11.1 \%$ (3/27) of the samples, all from captive animals. This is the first report of infection by these protozoans in this coati's species in the North region of Brazil; the South American coati may be participating as maintainers and disseminators of infectious agents to the environment and other hosts.
\end{abstract}

\section{INTRODUCTION}

Brazilian faunas are either free-living or in captive conditions living in zoological parks, conservation, scientific or commercial shelters, research institutes, or sorting and rehabilitation centers. These animals can be carriers and, therefore, reservoirs of zoonotic agents (SILVA, 2004). Lallo et al. (2009) report that anthropogenic environmental changes strongly affect the proliferation and occurrence of zoonotic parasitic diseases, such as cryptosporidiosis and giardiasis. However, studies on the zoonotic potential of protozoa from wild hosts is still incipient in Brazil (SOARES et al., 2008).
The South American coati (Nasua nasua Linnaeus, 1766) is a wild, carnivorous mammal widely distributed in South America and it lives in all Brazilian biomes; they are abundant in most places where they occur, especially in intact habitats, and there are apparently no significant threats to this species, but their population is probably reducing due to hunting and habitat loss caused by human action (BEISIEGEL; DE CAMPOS, 2013).

The scientific literature on the occurrence of Cryptosporidium spp. and Giardia spp. in wild mammals presents varied data, which are dependent on the species, geographic location, host food preferences, and seasonality, and even on results of samplings and

\footnotetext{
*Corresponding author: lenakassia7@hotmail.com
} 
diagnostic techniques used (APPELBEE, THOMPSON; OLSON, 2005).

Cryptosporidiosis can be caused by different species and subtypes of Cryptosporidium spp., and it affects different hosts. Clinical signs vary according to the host's age and health status, parasite species and subtype, and infectious dose (XIAO; FAYER, 2008).

In the most severe cases of this disease, the host can develop enteritis, colitis, cystitis, hepatitis, pancreatitis, and clinical respiratory symptoms such as sinusitis and pneumonia (CHALMERS; DAVIES, 2010). The period between ingestion of the oocysts and the occurrence of symptoms is 7 to 10 days, which can range from five to 28 days (PEREIRA et al., 2009).

Several factors affect the epidemiology of cryptosporidiosis: reduced and varied size of oocysts which allows their passage through filters usually employed in water treatment processes; low infectious doses the infectious dose of $C$. parvum ranges from 9 to 1,042 oocysts; and production of oocysts inside the hosts they are already infectious when eliminated by defecation, and both humans and animals participate as reservoirs of the agent in its biological cycle (SMITH et al., 2006). Other factors may contribute to the lack of information on the epidemiology of this parasite, such as the lack of the practice of disease notification by doctors and laboratories; moreover, the fecal tests used by most laboratories do not allow the identification of this parasite (VALENTIM; CARDOSO, 2011). Fayer and Xiao (2008) report that the Cryptosporidium spp. parasite load tends to be lower in wild mammals when compared to that found in domestic mammals.

From the epidemiological point of view, infection by Giardia spp. is more worrisome in animals because they show few clinical signs of infection and do not respond well to the treatments applied; thus, they serve as sources of infection because they can eliminate the Giardia spp. cysts through feces for months or even years (LALLO; RODRIGUES; BONDAN, 2003). The great majority of studies on Giardia spp. in wild mammals were made to evaluate the potential of these animals as reservoirs of disease for humans and cattle (APPELBEE; THOMPSON; OLSON, 2005).

Giardia spp. affects animals and humans, causing diarrhea the most common symptom and jeopardizes the digestion and absorption of food, which results in dehydration, weight loss, and death, especially in young animals and those with concomitant or debilitating diseases (MUNDIM et al., 2003). The number of cysts ingested by the host is an important factor for the pathogenesis of this disease. The ingestion of only 10 cysts is capable of causing the infection (LINDSAY; ZAJAC, 2009).
Cryptosporidium spp. and Giardia spp. are responsible for two of the most serious water-borne diseases. The scientific literature reports epidemiological studies on these agents in several hosts, including some wild species. However, there are no studies on captive or free-living $N$. nasua animals with infection from enteroprotozoa, in the state of Pará, Brazil. Therefore, the objective of this study was to present data on the occurrence of these agents in coati ( $N$. nasua) from the North region of Brazil, and contribute to the already existing information on the environmental, human, and animal health risks.

\section{MATERIAL AND METHODS}

This study was approved by the SISBIO (license No. 39285) and by the Ethics Committee for the Use of Animals of the Federal Rural University of Amazonia (UFRA) (authorization protocol No. 034/2014 CEUA 23084.022512/2014-18).

Twenty-seven fecal samples of $N$. nasua were collected and examined: two from free-living animals and 25 from captive animals. Free-living animals were considered animals that had been removed from their natural habitat and were kept in quarantine until their final destination of release or captivity.

Eight animals were classified as young and 19 as adults 11 females and 16 males. The samples were from animals from the municipalities of Belém Emílio Goeldi Museum of Pará, Rodrigues Alves Forest, Laboratory of Animal Pathology (LABOPAT) of the UFRA, Wildlife Clinic of the UFRA Veterinary Hospital, and Environmental Police Battalion (BPA); Capitão Poço Gavião Real Conservation Shelter; and Santarém Unama Zoo (ZOOUNAMA).

The species Nasua nasua (Linnaeus, 1766), the South American coati, from the family Procynidae was identified by morphological observations made by veterinarians of the collection locations, based on a comparison of the characteristics of the species described by Reis et al. (2010). This coati has a wide distribution in South America and is the only specie that can be found in the biomes Amazonia, Caatinga, Cerrado, Pantanal, Atlantic Forest, and Southern Fields.

All animals were housed in individual cages that were previously sanitized and lined with brown paper. Samples were collected between March 2015 and February 2017 in the enclosures where the animals were housed. Samples were collected immediately after defecation and without the need for containment of the animals. The samplings from free-living animals were carried out during the first 24 hours of their arrival at the management site in order to exclude probable parasitic infection of the animal at the site. In the case of animals subjected to necropsy in the LABOPAT (only two 
animals), the feces were collected directly from the animal's rectum. Data on sex, age, origin, and location were obtained for each animal.

Approximately $10 \mathrm{~g}$ of feces per animal were collected in the first hours of the collection days, or shortly after the animals were fed because feeding causes the animals to defecate more frequently. The material was immediately collected to avoid the environmental contamination of the samples. Subsequently, the samples were stored in sterile universal collection flasks without preservatives and kept under refrigeration until the analyses. The samples were processed within 48 hours after collection at the Laboratory of Enteroparasitosis in the Parasitology Department of the Evandro Chagas Institute in Ananindeua, Pará, Brazil. The central portion of the fecal samples was prioritized in the processing, due to its lower exposure to environmental contaminants.

The direct (lugol) and Kinyoun (modified Ziehl-Neelsen ZNm) methods were used for the diagnosis of Giardia spp. cysts and Cryptosporidium spp. oocysts, respectively. Two slides were prepared per sample and analyzed under light microscopy on 40x (for Giardia cysts) and 100x objectives (for Cryptosporidium oocyst).

A small aliquot of fecal material mixed with four to five drops of lugol was used on a glass slide and mounted under a cover slip $(24 \times 32 \mathrm{~mm})$ for microscopic observation for the direct examination.

Two grams of feces were used for the modified ZiehlNeelsen technique. The content was diluted and homogenized in a falcon-type tube containing $10 \mathrm{~mL}$ of buffered formalin that was filtered through folded gauze. Subsequently, about $4 \mathrm{~mL}$ of ether was added to the filtrate for centrifugation (2000 rpm for 5 minutes). The smear was made with one drop of the sediment that was stained with carbol fuchsin and observed under a microscope.

A commercial immunological method (RIDA®QUICK Cryptosporidium/Giardia Combi. ®R-Biopharm) was also employed to detect both parasite antigens simultaneously. The high indexes of sensitivity and specificity of this immunological method (above 90.0\%) makes it a complementary tool for the microscopic diagnosis and increases the probability of detecting these parasites. Low rates of protozoa excretion in feces decreases the sensitivity of microscopic methods; therefore, the use of this method may also contribute to improved results.

The immunochromatographic test was performed according to the manufacturer's protocol. A homogenate was made using $50 \mathrm{mg}$ of the sample that was diluted in $1 \mathrm{~mL}$ of extraction buffer. An aliquot of $0.5 \mathrm{ml}$ of the obtained supernatant was placed in contact with the strips containing the antibodies, and the readings were carried out after five minutes.

\section{RESULTS AND DISCUSSION}

The positivity for Cryptosporidium spp. oocysts in $N$. nasua was 11.1\% (3/27) (Figure 1), and was found in one young, male, free-living animal and in one male and one female captive adult animals. All three coatis had no diarrhea or any other clinical signs. The detection of Giardia spp. cysts was observed in $11.1 \%$ (3/27), all adult captive animals two males and one female; one of them had a clinical presentation of diarrhea (Figure 1). No co-infection was detected for both parasites.

Figure 1 - A. Positive sample for Cryptosporidium spp. oocysts stained by the modified Ziehl-Neelsen method (arrow). B. Positive sample for Giardia spp. cysts observed by the direct method (arrows).

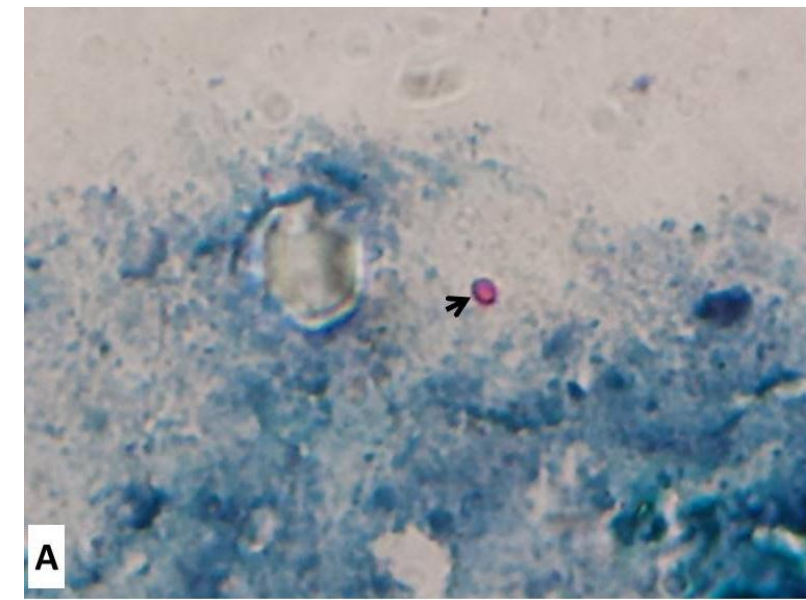

Source: Author's collection.
Oocysts and cysts of the agents were observed in the microscopic analyses (direct and ZNm methods). However, the immunological test showed concordance of

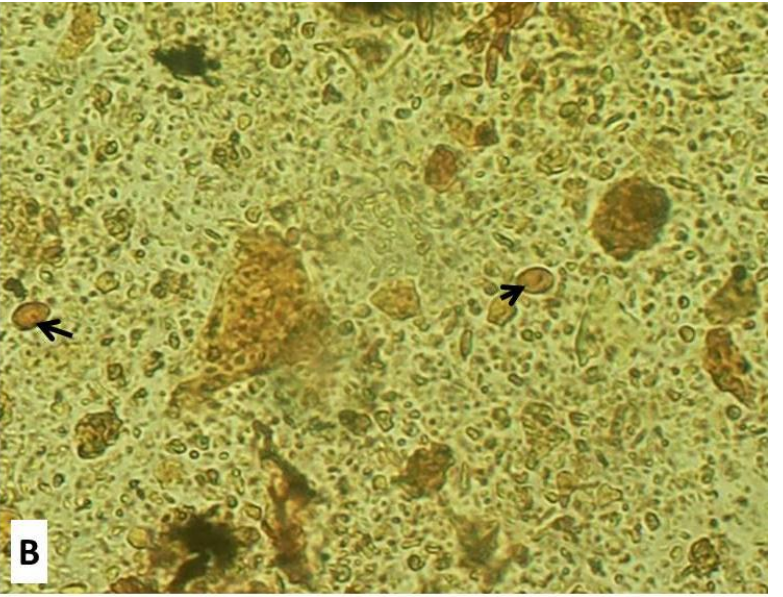

results only for Cryptosporidium spp.; the diagnosis of Giardia spp. was positive only by the direct method. The Giardia cyst observed under microscopy probably does 
not belong to the species $G$. lamblia for which the immunological test is indicated but to other species with Giardia spp. In addition, antigenic differences among the species of $G$. lamblia may have affected the results of the method. Molecular studies will aid in clarifying the observed disagreement; this shows the importance of using immunological tests for the diagnosis of these agents; they have the advantage of being fast, easy to perform, and do not require qualified technical personnel or equipment.

Occurrence of Cryptosporidium spp. and Giardia spp. has been reported in $N$. nasua specimens from other regions, both in captive and free-living animals, which was also observed in this study. In 2008, Farret et al. were the first to report the occurrence of Cryptosporidium spp. and Giardia spp. in samples of N. nasua from Brazil that were kept in a conservation shelter in Rio Grande do Sul state. Among the three specimens studied, only one had positive diagnosis, presenting mixed infection from Giardia spp., Cryptosporidium spp., and Cystoisopora spp. Subsequently, Bosa (2014) analyzed 128 fecal samples of mammals from the Municipal Zoo of Curitiba, Brazil, and all were negative for Cryptosporidium spp. The author used only specific techniques to detect Cryptosporidium, and did not perform search for Giardia.

More recently, Snak et al. (2015) examined fecal samples of seven captive $N$. nasua of the Municipal Zoo of Cascavel in Paraná, Brazil and found parasitism by Cryptosporidium spp. in three individuals.

Although only two specimens of free-living animals were evaluated in this study, the positive sample for Cryptosporidium spp. showed that this parasite occurs in $N$. nasua also in its natural habitat. However, this fact does not mean that parasitism by Giardia spp. is absent because both agents have the same mechanism of dissemination in the environment and have a great variety of hosts.

Studies in Brazil have demonstrated the circulation of these parasites in the wild environment. Dall'olio and Franco (2004) found high positivity (16.25\%) for Cryptosporidium spp. when analyzing samples of 240 wild mammals that were captured in three areas of the Atlantic Forest. Holsback et al. (2013) studied 38 wild free-living animals in rehabilitation centers of the São Paulo and Mato Grosso do Sul states, Brazil, and found the presence of Cryptosporidium spp. in five animals. Three animals were positive for Giardia spp., and one of them was from the N. nasua species.

Paziewska et al. (2007) investigated the occurrence of Cryptosporidium spp. in wild mammals in Poland 14 gray wolves, which are carnivorous like $N$. nasua and obtained $36 \%$ positivity. The authors suggested that these animals are important natural sources for maintaining Cryptosporidium spp. in the environment.
In 2011, Beck et al. studied 131 samples of mammals belonging to 57 species from a zoo in Croatia, and found high occurrence (29.0\%) of Giardia spp. using the immunofluorescence technique. The authors reported that none of the animals analyzed presented symptoms related to giardiasis; thus, contradicting to the data of this study: one of the positive coatis for this parasite had a clinical presentation of diarrhea. Complementary studies must be performed to clarify this correlation, since other infectious agents may cause diarrheal disease in animals.

However, the positive animals for Cryptosporidium spp. in this study were asymptomatic. A similar result was observed by Rasambainarivo et al. (2013) in Madagascar lemurs parasitized by Cryptosporidium spp. with negative results for Giardia spp. It is important to point out that infectious agents have different degrees of pathogenicity, and it is possible that not all parasitized hosts show clinical signs of infection or present subclinical infection. Therefore, these individuals are asymptomatic the main maintainers of the epidemic chain of agents, which contributes to the maintenance and dissemination of the agents in the environment.

Hodžić; Alić; Omeragić (2014) investigated 123 fecal samples of red foxes (Vulpes vulpes) in Bosnia and Herzegovina, using immunofluorescence, and observed a prevalence of $3.2 \%$ Cryptosporidium spp. and $7.3 \%$ Giardia duodenalis.

More recently, Saki; Foroutan-rad; Asadpouri (2016) studied wild rodents in Ahvaz, Iran, using a ZNm technique and polymerase chain reaction (PCR) for Cryptosporidium spp. and found 3\% of positive samples, which is a result slightly lower than that found in $N$. nasua in this study.

Bittner et al. (2010) stated that wild animals, both freeliving and captive, might be infected with Cryptosporidium spp. and Giardia spp., and that the interaction of these animals is increasing with humans; unfortunately, the number of complaints about coatis in houses and urban areas close to forest fragments is increasing because they are constantly seeking housing and food. The participation of $N$. nasua as well as other wild and domestic mammals as host reservoirs in the dissemination of such agents cannot be underestimated because of its direct effect on human, animal, and environmental health.

In epidemiological terms, a large variation of occurrence levels for Cryptosporidium spp. and Giardia spp. in wild mammals from different regions of the country and the world is observed. Thus, new studies on wild animals within their environment will better clarify about the epidemiology of these agents in the Amazon region. Moreover, these parasites circulate more in captivity because of their maintenance and dissemination in these 
environments, which shows the importance of periodic evaluations and identification of the probable sources of infection in the animals.

\section{CONCLUSIONS}

The study proves the presence of the agents Cryptosporidium spp. and Giardia spp. in South American coati (Nasua nasua) that are kept in shelters in the state of Pará, Brazil. These animals can act as sources of infection for humans and other animals. This is the first report of infection by these protozoans in the Nasua nasua species in the North region of Brazil. Further molecular studies are needed to elucidate the pathogenic and zoonotic potential of these agents at the regional level.

\section{ACKNOWLEDGEMENTS}

The authors thank the Federal Rural University of the Amazon UFRA;

The Evandro Chagas Institute (IEC)/MS - Parasitology: Laboratory of intestinal enteroparasitosis;

The Environmental Police Battalion of the State of Pará (BPA-PA);

The Unama Zoo (ZOOUNAMA);

The Rodrigues Alves Forest;

The Emílio Goeldi Museum of Pará;

The Gavião Real Conservation Shelter.

\section{REFERENCES}

APPELBEE, A. J.; THOMPSON, R. C. A.; OLSON, M. E. Giardia and Cryptosporidium in mammalian wildlife - Current status and future needs. Trends Parasitol, v. 21, n. 8, p. 370-376, 2005.

BEISIEGEL, B. M.; DE CAMPOS, C. B. Avaliação do risco de extinção do Quati Nasua nasua (Linnaeus, 1766) no Brasil. A Avaliação do Estado de Conservação dos Carnívoros. Biodiver Bras, v. 3, n. 1, p. 269-276, 2013.

BECK, R. et al. Prevalence and molecular typing of Giardia spp. in captive mammals at the zoo of Zagreb, Croatia. Vet Parasitol, v. 175, n. 1-2, p. 40-46, 2011.

BITTNER, G. C. et al. Coati (Nasua nasua) attacks on humans: report. Wilderness Environ Med, n. 21, p. 349-52, 2010.

BOSA, C. R. Detecção e identificação de Cryptosporidium spp. tyzzer, 1907 em fezes de animais e em água do Zoológico Municipal de Curitiba, Paraná, Brasil. 2014. 109 f. Tese (Doutorado em Microbiologia, Parasitologia e Patologia) - Universidade Federal do Paraná, Curitiba, 2014.

CHALMERS, R. M.; DAVIES, A. P. Minireview: clinical cryptosporidiosis. Exp Parasitol, v. 124, p. 138-146, 2010.

DALL'OLIO, A. J.; FRANCO, R. M. B. Ocorrência de Cryptosporidium spp. em pequenos mamíferos silvestres de três áreas serranas do Sudeste brasileiro. Arq Bras Med Vet Zoot, v. 56, n. 1, p. 25-31, 2004.

FARRET, M. H. et al. Parasitismo por protozoários gastrointestinais em carnívoros silvestres mantidos em cativeiro no sul do Brasil. RPCV, v. 103, p. 93-95, 2008.
FAYER, R.; XIAO, L. Cryptosporidium and Cryptosporidiosis. Boca Raton: IWA Publishing, CRC Press, 2008. 576 p.

HODŽIĆ, A.; ALIĆ, A.; OMERAGIĆ, J. Occurrence of Cryptosporidium spp. and Giardia duodenalis in red Foxes (Vulpes vulpes) in Bosnia and Herzegovina. Mac Vet Ver, v. 37, n. 2, p. 189-192, 2014.

HOLSBACK, L. et al. Infecção natural por endoparasitas em animais silvestres de vida-livre. Rev Bras Parasitol Vet, v. 22, n. 2, p. 302-306, 2013.

LALLO, M. A.; RODRIGUES, L. C. S.; BONDAN, E. F. Giardíase em cães e gatos- revisão. Rev Clín. Vet, v. 43, p. 40-44, mar.-abr., 2003.

LALLO, M. A.; et al. Ocorrência de Giardia, Crytosporidium e microsporídios em animais silvestres em áreas de desmatamentos no Estado de São Paulo, Brasil. Ciên Rural, Santa Maria, v. 39, n. 5, p. 1465-1470, ago. 2009.

LINDSAY, D. S.; ZAJAC, A. M. The Biology and Control of Giardia spp. and Tritrichomonas foetus. Vet Clin N Am: Small Anim Pract, v. 39, n. 6, p. 993-1007, 2009.

MUNDIM, M. J. S. et al. Frequência de Giardia spp. por duas técnicas de diagnóstico em fezes de cães. Arq Bras Med Vet Zoot, v. 55, n. 6, p. 770-773, 2003.

PAZIEWSKA, A. et al. Distribution of Cryptosporidium and Giardia spp. In selected species of protected and game mammals from northeastern Poland. Ann Agric Environ Med, v. 14, p. 265-270, 2007.

PEREIRA, J. T. et al. Cryptosporidium spp.: para controlar é necessário conhecer. Rev Saúde Amb, v. 10, n. 2, p. 1-25, 2009.

RASAMBAINARIVO, F. T. et al. Survey of Giardia and Cryptosporidium in lemurs from the Ranomafana National Park, Madagascar. J Wildl Dis, v. 49, n. 3, p. 741-743, 2013.

REIS, N. R. et al. Mamíferos do Brasil: guia de identificação. Ed1ㅇ․ Technical Books Editora. 2010, p.490.

SAKI, J.; FOROUTAN-RAD, M.; ASADPOURI, R. Molecular Characterization of Cryptosporidium spp. in Wild Rodents of Southwestern Iran Using 18s rRNA Gene Nested-PCR-RFLP and Sequencing Techniques. J Trop Med. Article ID 6834206, 6 p. 2016.

SILVA, J. C. R. Zoonoses e doenças emergentes transmitidas por animais silvestres. 2004. Disponível em: <http:/www.abravas.com.br/ 03 zoonoses\%20e\%20Doen\%E7as\%20Emergentes.PDF.> . Acesso em: 20 de agosto de 2014 .

SMITH, H. V. et al. Tools for investigating the environmental transmission of Cryptosporidium and Giardia infections in humans. Trends Parasitol, v. 22 n. 4, p. 160-167, 2006.

SNAK, A. et al. Ocorrência de Cryptosporidium spp. em animais silvestres do Parque municipal de Cascavel, Paraná, Brasil. Semin: Cien Agrar, v. 36, n. 6, suplemento 2, p. 4323-4332, 2015.

SOARES, J. F. et al. Parasitismo por Giardia sp. e Cryptosporidium sp. em Coendou villosus. Ciên Rural, Santa Maria, v. 38, n. 2, p. 23-24, 2008.

VALENTIM, T.; CARDOZO, S. V. Avaliação qualitativa de oocistos de Cryptosporidium sp. em amostras fecais de pacientes atendidos no Instituto Fernandes Figueira/Fiocruz. Saúde Amb Rev, Duque de Caxias, v. 6, n. 1, p. 11-16, 2011.

XIAO, L.; FAYER, R. Molecular characterisation of species and genotypes of Cryptosporidium and Giardia and assessment of zoonotic transmission. Int J Parasitol, v. 38, n. 11, p. 1239-1255, 2008. 